\title{
Die kirchenslavische Zeile in den Petersburger Vocabularia comparativa (1787-1789)*
}

\author{
Helmut Keipert \\ Universität Bonn \\ h.keipert@uni-bonn.de
}

\begin{abstract}
:
"The Church-Slavonic Lines in the Vocabularia comparativa (St. Petersburg, 1787-89)" Edited in 1787 and 1789 by Peter Simon Pallas, the two-volume dictionary Linguarum totius orbis vocabularia comparativa, by Catherine II, contains equivalents in 200 languages (among them twelve Slavic ones) for 285 elementary Russian words. The present article discusses the entries written for Church Slavonic, a Slavic language without native speakers and without complete dictionaries (not to mention bilingual Russian-Church Slavonic ones). The author offers a detailed comparison of the Church Slavonic lines with the Russian head-words, distinguishes several types of head-words in the dictionary, and identifies what might be a French subtext for some of the Russian head-words in the second volume of the Vocabularia. The article offers a characterization of the lexicographic skills of the still-unknown, lateeighteenth-century compiler of the Church Slavonic word-list and suggests that his obvious familiarity with the vocabulary of Church Slavonic texts could not make up for his ignorance of the theoretical problems posed by a translation between two languages regarded by many contemporaries as one and the same.
\end{abstract}

Keywords: Church Slavonic, Dictionaries, Translation, Lexicography, Catherine II, Peter Simon Pallas, Josef Dobrovský

"Wer soll dieß errathen?" J. Dobrovský

1. Die Vocabularia comparativa und die Entstehung der slavischen Sprachwissenschaft

Im Auftrag und auf Kosten Katharinas II. haben Akademiemitglied Peter Simon Pallas (1741-1811) und der an der Akademiebibliothek tätige Johann Bacmeister (1732?1788) sowie nach dessen Tod Christian Gottlieb Arndt (1743-1829) in den Jahren 1786/7 und 1789 als Redakteure die ersten zwei Bände der von der Zarin konzipierten Linguarum totius orbis vocabularia comparativa; Augustissimae cura collecta (russischer Titel: Sravnitel'nye slovari vsech jazykov i narečij, sobrannye desniceju Vsevysočajšeij Osoby) zum Druck gebracht. ${ }^{1}$ Die slavischen Sprachen nehmen in diesem monumentalen Werk einen prominenten Platz ein, denn in den insgesamt 285

\footnotetext{
* Einem anonymen Rezensenten habe ich für sachkundig-kritische Hinweise zur Verbesserung der Darstellung sehr zu danken.

${ }^{1}$ Peter Simon Pallas (Hrsg.), Linguarum totius orbis vocabularia comparativa. Band 1. Nachdruck der Ausgabe St. Petersburg 1786; Band 2. Nachdruck der Ausgabe St. Petersburg 1789. Herausgegeben und mit einem Vorwort versehen von Harald Haarmann (Hamburg: Helmut Buske Verlag, 1977-1978). Vgl. Friedrich von Adelung, Catherinens der Grossen Verdienste um die Vergleichende Sprachenkunde. Nachdruck der Ausgabe von 1815 mit einer Einleitung und einem bio-bibliographischen Register von Harald Haarmann (Hamburg: Helmut Buske Verlag, 1976).
} 
Wortartikeln für 200 europäische und asiatische Sprachen und Dialekte schließen sich an das den betreffenden Begriff auf russisch vorgebende Lemma jeweils als erste Gruppe unter den Zeilennummern 1-12 die hier erfaßten weiteren Slavinen an:
1. Славянскій;
2. Славяно-Венгерскій;
3. Иллирійскій;
4. Богемскій;
5. Сербскій;
6. Вендскій;
7. Сорабскій,
8. Полабскій;
9. Кашубскій;

10. Польскій; 11. Малороссійскій; 12. Суздальскій.

Die Spitzenstellung des Slavischen und insbesondere des Russischen wird verständlicher, wenn man bedenkt, daß die im Hintergrund der Publikation wirkende Zarin bei ihrem Vorhaben vielleicht sogar darauf gehofft haben könnte,"die Sprachforschung würde letzten Endes den Nachweis erbringen, daß die Mutter aller Sprachen der Welt in Rußland, auf dem Territorium ihres Riesenreiches also, zu suchen sei." ${ }^{2}$ Trotz seiner zahlreichen Unzulänglichkeiten und z. T. groben Fehler hat dieser slavische Teil des Petersburger Lexikons in der Geschichte der Slavischen Philologie eine besondere Rolle gespielt. Mit der großen Zahl und der Vielgestaltigkeit seiner Wortbelege hat er es ermöglicht, daß der nicht zu Unrecht als einer der "Väter" der Slavistik bezeichnete tschechische Gelehrte Josef Dobrovský (1753-1829) das ihm schon seit einiger Zeit vorschwebende Modell einer Aufteilung des slavischen Sprachgebiets in zwei Zweige ${ }^{3}$ so gut exemplifizieren konnte, daß es kurz danach nur noch der ergänzenden Absonderung des Russischen durch Aleksandr Vostokov (17811864) bedurfte, um die auch heute noch weithin akzeptierte Dreiteilung des Slavischen in Westslavisch, Südslavisch und Ostslavisch entstehen zu lassen. Im einzelnen verfolgen läßt sich dieser für die sprachwissenschaftliche Konstituierung unseres Fachs wichtige Schritt in der kleinen Abhandlung Vergleichung der Russischen und Böhmischen Sprache. Nach dem Wörterverzeichnisse des Petersburger VergleichungsWörterbuchs, die Dobrovský 1796 der Buchausgabe seines Berichts über die 1792 auf Veranlassung der Königlichen böhmischen Gesellschaft der Wissenschaften unternommene neunmonatige Studienreise nach Schweden und Rußland angefügt hat. $^{4}$

\footnotetext{
${ }^{2}$ Harald Haarmann, "Das Wörterbuchprojekt Katharinas der Großen: Ein Paradebeispiel aufklärerischer Kulturpolitik in Russland," European Journal of Semiotic Studies 11 (1999): 207-258, hier, 230.

${ }^{3}$ Wie er seinem Freund Fortunat Durich in einem Brief vom 10. August 1794 mitteilt, hat er sich dabei von der Zweiteilung des Deutschen in Ober- und Niederdeutsch leiten lassen: "Si recte Procopius habet, cur non in lingua slavica generatim sumta tales notas deprehendere liceat, quales in l. germanica, ut discrimen, uti inter germanicam superiorem et inferiorem, statui possit constans atque notabile. Videorque mihi deprehendisse tale aliquid in l. slav. Igitur linguae discrimina antiquioria haec notavi." ["Wenn Prokop recht hat, warum sollte man dann nicht in der slavischen Sprache als ganze genommen ebensolche Merkmale entdecken, wie sie in der deutschen Sprache als ständiger und bemerkenswerter Unterschied etwa zwischen dem Ober- und Niederdeutschen festzustellen sind. Ich meine so etwas in der slavischen Sprache entdeckt zu haben. Deshalb habe ich die folgenden älteren Sprachunterschiede notiert."] Korrespondence Josefa Dobrovského. Díl I. Vzájemné dopisy Josefa Dobrovského a Fortunata Duricha z let 1778-18oo. K vydání vypravil Adolf Patera (V Praze: Nákladem České Akademie Císaře Františka Josefa pro vědy, slovesnost a umění, 1895), 320.

${ }^{4}$ Vgl. Helmut Keipert, "Die Pallas-Redaktion der Petersburger Vocabularia comparativa und ihre Bedeutung für die Entwicklung der slavischen Sprachwissenschaft," Historiographia Linguistica 40:1 (2013), 121-149. Ich benutze die Gelegenheit zur Korrektur eines bedauerlichen Fehlers in meiner Publikation: auf S. 122 habe ich als Mitredakteur der Vocabularia versehentlich Hartwich Ludwig Christian Bacmeister (1730-1808) genannt, weil von diesem umfangreiche sprachvergleichende Studien bekannt sind, während in biographischen Artikeln zu Johann (Ivan Grigor'evič) Bacmeister die
} 


\section{Die Sonderstellung der kirchenslavischen Zeile in den Vocabularia}

Erstaunlicherweise hat sich Dobrovský in seiner vor allem dem Tschechischen und Russischen gewidmeten Vergleichung nur beiläufig mit Wörtern der Kirchenslavisch-Zeile der Vocabularia beschäftigt, aber auch nach ihm scheint niemand mehr auf die schwierigen Probleme eingegangen zu sein, die unter den Slavica die Ermittlung gerade des kirchenslavischen Wortguts aufgeworfen haben muß. Bekanntlich ist das für das Petersburger Lexikon erforderliche Material aus den berücksichtigten 200 Sprachen vor allem auf drei Wegen gewonnen worden. Gemeinsame Grundlage für alle Beiträger war eine kleine Schrift mit dem Titel Modèle du vocabulaire, qui doit servir à la comparaison de toutes les langues, die 1786 in St. Petersburg gedruckt worden ist und eine Liste der von Katharina II. zum Vergleich bestimmten 285 Probewörter in russischer Sprache und deren Übersetzung ins Lateinische, Deutsche und Französische enthielt. Verbreitet wurde dieser Fragebogen im Auftrag der Zarin auf dem Dienstweg über die Verwaltungsinstanzen des Russischen Reichs, aber er ist auch allen russischen Gesandten an auswärtigen Höfen sowie an viele Gelehrte im Ausland geschickt worden mit der Bitte, die Probewörter möglichst schnell in alle auch nur erreichbare Sprachen zu übersetzen bzw. von jeweils Sprachkundigen übersetzen zu lassen. ${ }^{5}$ Neben den Antworten auf diesen Fragebogen standen für die Erarbeitung der Einträge in Petersburg bereits manche Wortsammlungen namentlich für Sprachen indigener Völker des Russischen Reichs zur Verfügung, die aus den Expeditionen verschiedener Forschungsreisender hervorgegangen waren, und heranziehen ließen sich zudem die zahlreichen Sprachproben, die ein Jahrzehnt zuvor Hartwich Ludwig Christian Bacmeister mit einem etwas anders aufgebauten Fragebogen erfolgreich gesammelt hatte. ${ }^{6}$ Schließlich konnte man - ergänzend oder zur Kontrolle - zumindest für einige Sprachen auf in Petersburg vorhandene Wörterbücher zurückgreifen, zumal Katharina II. Friedrich Nicolai (1733-1811) in Berlin kurzfristig damit beauftragt hatte, für sie eine Übersicht über alle Sprachen der Welt und über deren bisherige Beschreibungen zu verfassen, und aus dieser Liste sind dem Vernehmen nach mehrere Werke für die Kaiserliche Bibliothek der Eremitage auch angeschafft worden. ${ }^{7}$ Von den anderen in den Vocabularia berücksichtigten Slavinen unterschied sich das auf der ersten Zeile unter dem russischen Lemma einzutragende Kirchenslavische einerseits dadurch, daß es wenn nicht schon seit seinen Anfängen dann zumindest im 18. Jh. eine "Sprache ohne Volk" gewesen ist, also nicht über "native speakers" verfügte, die auf Grund einer natürlichen Sozialisation über diese Sprache geläufig und repräsentativ-

\footnotetext{
Beteiligung an diesem Wörterbuch gewöhnlich nicht erwähnt wird, vgl. z. B. Galina Nikolaevna Moiseeva,"Bakmejster, Ivan Grigor'evič (Bacmeister, Johann)," in Slovar' russkich pisatelej XVIII veka. Vypusk 1 (A-I) (Leningrad: "Nauka," Leningradskoe otdelenie, 1988), 53-54. Roger Comtet, "Le dictionnaire plurilingue de Pallas (1787-1789) au carrefour des idées linguistiques de son temps," Cahiers de l'Institut de Linguistique et des Sciences du Langage 37 (2013): 7-34, hier 11-12, Anm. 23, hat darauf hingewiesen, daß sie in dieser Funktion schon öfter verwechselt worden seien, da man annehmen könne, daß sie mehr oder weniger beide an dem Wörterbuchprojekt beteiligt gewesen seien.

${ }^{5}$ Adelung, Catherinens der Grossen Verdienste um die Vergleichende Sprachenkunde, 52-54.

${ }^{6}$ Ibid., 23-32; Annelies Lauch, Wissenschaft und kulturelle Beziehungen in der russischen Aufklärung. Zum Wirken H. L. Ch. Bacmeisters (Berlin: Akademie-Verlag, 1969), 170-211.

${ }^{7}$ Adelung, Catherinens der Grossen Verdienste um die Vergleichende Sprachenkunde, 42-47.
} 
verläßlich hätten Auskunft geben können. ${ }^{8}$ D. h., um 1785 konnte man in Petersburg oder anderenorts bestenfalls gute Kenner des Kirchenslavischen befragen, ${ }^{9}$ die ihr Wissen durch regelmäßige Teilnahme am russisch-orthodoxen Gottesdienst, durch das Studium der inzwischen geschaffenen Kirchenslavisch-Grammatiken und einiger kleinerer Lexika ${ }^{10}$ sowie durch eine intensive Beschäftigung mit den Büchern des Cerkovnyj krug und anderen Texten des kirchenslavischen Schrifttums erworben hatten. Auf der anderen Seite kann im Rußland des 18. Jh. für einen orthodoxen Informanten das Kirchenslavische nicht ohne weiteres eine so fremde Sprache gewesen sein, wie es Polnisch, Tschechisch, Serbisch oder Wendisch zweifellos für ihn waren: Kirchenslavisches begegnete ihm täglich wie selbstverständlich in der Welt seines Glaubens, aber auch in den zahlreichen Entlehnungen aus dem kirchenslavischen Schrifttum, die z. T. semantisch säkularisiert auch im russischen Wortschatz dieser Zeit vertreten waren. Die Aufgabe dieses anonym gebliebenen Bearbeiters bestand im wesentlichen darin, zu entscheiden, welche der ihm als Lemma vorgegebenen russischen Wörter er auch im Kirchenslavischen (was immer er darunter verstand) für akzeptabel hielt und in seine Liste übernehmen konnte und welche dieser Wörter er lieber durch andere ersetzen oder wenigstens ergänzen wollte (weil sie seiner Meinung

\footnotetext{
${ }^{8}$ Dieser besondere Umstand schränkt auch in unserer Zeit die Möglichkeiten linguistischer Definitionen und Beschreibungen des Kirchenslavischen erheblich ein, vgl. Helmut Keipert, "KirchenslavischBegriffe," in Die slavischen Sprachen. Ein internationales Handbuch zu ihrer Struktur, ihrer Geschichte und ihrer Erforschung. Herausgegeben von Sebastian Kempgen [u.a.] (Berlin: de Gruyter, 2014), Bd. 2, 1211-1251, und zu dieser Besonderheit schon aus dem Jahre 1577 die polemisch-markante Aussage des polnischen Jesuiten Piotr Skarga über das Kirchenslavische: "Z słowieńskiego języka nigdy żaden uczonym być nie może. A już go teraz przecie prawie nikt doskonale nie rozumie. Bo tey na świecie naciej[...] nie masz[,] któraby im tak, jako w księgach jest, mówiła[,] a swych też regul, gramatyk i kalepinów do wykładu niema, ani już mieć może." ["Von der (kirchen)slavischen Sprache kann niemals jemand gelehrt werden. Und schon jetzt versteht sie doch fast niemand mehr vollkommen. Denn auf der Welt gibt es das Volk nicht, das sie so, wie sie in den Büchern steht, spräche, und zur Erklärung hat sie keine eigenen Regeln, Grammatiken und Wörterbücher und kann sie auch nicht mehr haben."] Zitiert nach Antoine Martel, La langue polonaise dans les pays ruthènes. Ukraine et Russie Blanche. 1569-1667 (Travaux et mémoires de l'Université de Lille. Nouvelle série: Droit et lettres, 20) (Lille, 1938), 69.

${ }^{9}$ Insofern ähnelte die Situation des Kirchenslavischen bei der Arbeit an den Vocabularia derjenigen des Lateinischen, das gleichfalls niemandes Muttersprache war, doch wurde das Lateinische auch im Rußland des 18. Jh. - ganz anders als das Kirchenslavische - im Schulunterricht intensiv gelernt, es wurde das Übersetzen aus der Muttersprache ins Lateinische geübt, auswendig beherrschte Gesprächsbücher ("Colloquia") konnten die Fortgeschrittenen allmählich zu freiem mündlichen Gebrauch der Sprache führen, und umfangreiche zweisprachige "passive" und "aktive" Lexika ermöglichten kontrolliertes Übersetzen aus dem Lateinischen ebenso wie in das Lateinische.

${ }^{10}$ Einen systematisch auch das Kirchenslavische einbeziehenden "Calepinus," der den Wortschatz dieser Sprache vom Lateinischen her hätte erschließen können, gab es trotz Skargas Bemerkung noch immer nicht, denn die einige Zeit lang als Handschrift auch in Rußland verbreitete Calepinus-Bearbeitung von Je. Slavynec'kyj aus der Mitte des 17. Jh. hatte als Zielsprache das Ruthenische. Vgl. Leksykon latyns'kyj Je. Slavynec'koho. Leksykon sloveno-latyns'kyj Je Slavynec'koho ta A. Korec'koho-Satanovs'koho. Pidhotuvav do vydannja V. V. Nimčuk (Kyjiv: Vydavnictvo "Naukova dumka," 1973). Der 1627 in Kiev erschienene Leksykon slavenorosskyj des Pamva Berynda erklärte in seinen etwa 5000 Artikeln auf ruthenisch vor allem in kirchenslavischen Texten auftretende "hard words," während die 1704 unter der Sprachbezeichnung "славенский” im Leksikon trejazyčnyj des Fedor Polikarpov zusammengetragenen etwa 20000 "slavisch-russischen" Wörter nicht im einzelnen spezifiziert werden, vgl. F. Polikarpov, Leksikon trejazyčnyj. Dictionarium trilingue. Moskva 1704. Nachdruck und Einleitung von Helmut Keipert (München: Kubon \& Sagner, 1988), XIII. Diese umfangreicheren Wörterbücher sind also für die hier angeordnete Suche nach russisch-kirchenslavischen Äquivalenten kaum geeignet gewesen. Auch sonst hat sich die Verwendung lexikographischer Hilfsmittel bisher nicht nachweisen lassen, vgl. 4 .
} 
nach dort nicht belegt oder dafür nicht typisch waren). Leider wissen wir nicht, welchen allgemeinen Grundsätzen er bei seiner Wortwahl gefolgt ist, geschweige denn wie er seine Entscheidung in jedem einzelnen Fall begründet hat - wir können im Nachhinein nur feststellen, zu welchem Ergebnis er bei seiner Arbeit gekommen ist (vgl. 3.), und daran einige Vermutungen darüber anschließen, wie er vielleicht bei seiner Suche nach dem jeweils geeigneten kirchenslavischen Wort vorgegangen ist (vgl. 4.). Wie schwierig die hier von ihm erwartete Grenzziehung zwischen russischem und kirchenslavischem Wortgut gewesen sein muß, kann man sich bereits an der Tatsache veranschaulichen, daß in dem seit 1783, also praktisch gleichzeitig, in Petersburg vorbereiteten ersten normativen Russisch-Wörterbuch, dem Slovar' Akademii Rossijskoj (1789-1794), nicht weniger als 3549 der insgesamt über 43000 Wörter mit der Markierung “сл(авенское)” aufgenommen worden sind ${ }^{11}$ und immer wieder sogar ganz alltägliche russische Wörter wie рука auch mit kirchenslavischen Bibelstellen exemplifiziert werden!

\section{Russische Lemmata und kirchenslavische Äquivalente im Vergleich}

Während Dobrovský seine 285 russisch-tschechischen Paarungen der Reihe nach Wort für Wort verglichen hat, soll hier der Versuch gemacht werden, die russisch-kirchenslavischen Paare übersichtlicher nach der Struktur der russischen Lemmata und der ihnen entsprechenden kirchenslavischen Äquivalente zusammenzustellen. Die gedruckten Vocabularia weisen drei Arten russischer Lemmata auf, nämlich:

1) 254 einfache wie Nr. 1. БОГЪ, in denen nur ein einziges russisches Wort in Versalien über dem Artikel steht (vgl. 3.1.)

2) 19 komplexe wie Nr. 152. КОНЬ, ЛОШАДЬ, Nr. 184. СТОРОЖЪ, (караулъ) oder Nr. 233. ВЗЯТь (Брать, Имать, Принять), in denen noch ein weiteres Wort oder mehrere gleichfalls in Versalien oder in nachgestellten Klammern vorgegeben werden (vgl. 3.2.)

3) 12 Angaben in Ziffern wie "1," "10," oder "10oo" im Anhang "Čisla evropejskich i aziatskich narodov," ${ }^{12}$ in denen das russische Wort nicht mehr über dem Artikel steht, sondern auf dessen erster Zeile das Kirchenslavische in die zweite verdrängt hat, in denen auf das Böhmische nun in der fünften Zeile neu das Mährische in der sechsten folgt und damit, anders als in den 273 Artikeln zuvor, insgesamt vierzehn slavische Sprachen vertreten sind (vgl. 3.3.).

Es fällt auf, daß die komplexen Lemmata erst 1789 im zweiten Band auftreten, und man könnte daran denken, daß der Zweck dieser verschiedenen Zusätze die

\footnotetext{
${ }^{11}$ Vera Viktorovna Zamkova, Slavjanizm kak stilističeskaja kategorija v russkom literaturnom jazyke XVIII v. (Leningrad: Izdatel'stvo "Nauka," Leningradskoe otdelenie, 1975), 21. Elena Ėduardovna Biržakova, "Leksikografija XVIII veka," in Istorija russkoj leksikografii. Otvetstvennyj redaktor Fedor Pavlovič Sorokoletov (Sankt-Peterburg: "Nauka," 1998), 59-126, hier 107, 109, spricht von "12\%" (statt "ein Zwölftel”?) so bezeichneter Lexik und gibt noch höhere Gesamtzahlen an, nämlich alles in allem "не менее 5500о."

${ }^{12}$ Linguarum totius orbis vocabularia comparativa, Band 2: 471-491.
} 
Präzisierung der mit dem Lemmawort zu verbindenden Bedeutung gewesen ist, doch leuchtet diese Überlegung keineswegs immer ein. Noch merkwürdiger ist allerdings, daß die dem zweiten Band später vorangestellte "Rospis' slovam v dvuch častjach per'vogo otdelenija nachodjaščimsja," ${ }^{13}$ trotzdem nur einfache russische Lemmata aufweist und doch bei einigen Worterklärungen für den zweiten Band mehr als nur ein einziges lateinisches Äquivalent nennen darf, während es für den ersten Band nicht mehr zu solchen Ergänzungen gekommen ist. ${ }^{14}$ Warum der Bearbeiter bei manchen kirchenslavischen Wörtern Akzentzeichen gesetzt hat, ist nicht zu erkennen, denn in den hier zu zitierenden Formen unterscheidet sich der Akzentsitz nicht von demjenigen in der jeweiligen russischen Form (wo er niemals angegeben wird); da das Wörterbuch die kirchenslavischen Wörter in Zivilschrift schreibt, hat es den Gravis im vokalischen Wortformenauslaut durch den Akut ersetzt. Man beachte zudem, daß die Vocabularia beim kyrillischen Transkribieren lateinisch geschriebener Wortformen in Ermangelung geeigneter Buchstaben Akzentzeichen auch als Diakritika verwenden und dabei mit dem Zirkumflex $<^{\wedge}>$ über dem Buchstaben $<$ Ю $>$ die russische Verbindung $j u$ bezeichnen (vgl. лю^ бumь), während der Akut darüber französisches $u$ darstellt (vgl. сю' $p=$ sur) ${ }^{15}$ Fehlerhafte Schreibungen der Vocabularia werden hier durch Unterstreichen des betreffenden Buchstabens markiert.

3.1. Bei den einfachen Lemmata lassen sich sieben verschiedene kirchenslavische Äquivalenttypen unterscheiden.

3.1.1. Die kirchenslavische Wortform stimmt mit der russischen völlig überein; das betrifft 111 Eintragungen, wenn man das unter Nr. 79 stehende ksl. въmmp fehlerhaft geschriebenen russischen Lemma ВБТР $\underline{b}$ und unter Nr. 30 das fehlerhafte ksl. язикъ mit dem Lemma ЯЗЫКЪ gleichsetzt. Genannt wird hier nur die auf der Kirchenslavisch-Zeile geschriebene Wortform:

Bd. 1: 1. Богъ; 3. Отецъ; 5. Сынъ; 6. Дочь; 7. Братъ; 9. Мужъ; 10. Жена; 14. Человђкъ; 18. Носъ; 19. Ноздри; 21. Брови; 29. Зубъ; 3о. Язикъ;34. Локоть; 35. Рука; 40. Нога; 41. Кольно; 42. Кожа; 43. Мясо; 44. Кость; 45. Кровь; 46. Сердце; 48. Слухъ; 49. Зрьнїе; 5о. Вкусъ; 51. Обонянїе; 52. Осязанїе; 54. Имя; 59. Сонъ; 62. Трудъ; 66. Власть; 70. Духъ; 73. Кругъ, 75. Солнце; 76. Мъсяцъ; 77. Звъзда; 78. Лучъ; 79. Вђтръ [sic!]; 8о. Вихрь; 81. Буря; 82. Дождь; 83. Градъ; 84. Молнїя; 85. Снъгъ; 86. Ледъ; 87. День; 88. Ночь; 89. Утро; 91 Льто; 92. Весна; 97. Земля; 99. Море; 10о. Рђка; 101. Волны; 102. Песокъ; 108. Холмъ;

\footnotetext{
${ }^{13}$ Linguarum totius orbis vocabularia comparativa, Band 2: XI-XIV.

${ }^{14}$ Diese Übersicht irritiert auch insofern, als sie manche Lemmata anders, aber durchaus nicht immer richtiger als im zuvor gedruckten Haupttext schreibt, vgl. z. B. Nr. 20 Глазъ (: ГЛАСъ), Nr. 26 Щеки (:

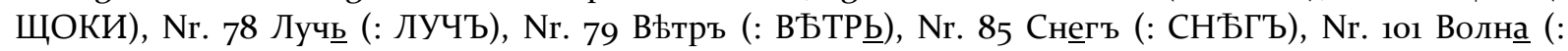

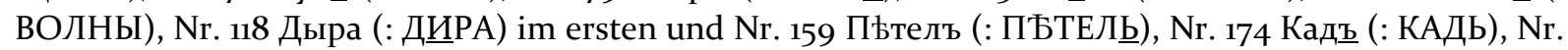
205 Ниско (: НИЗКО), Nr. 256 Чемъ (: ЧЪМъ) im zweiten Band. Die bei Nr. 156 Мышъ ausgebliebene

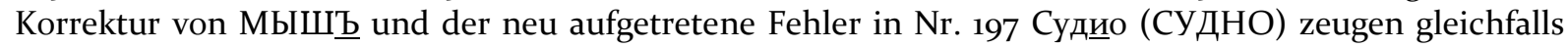
nicht von besonderer Aufmerksamkeit bei der Herstellung des Bandes.

${ }^{15}$ Linguarum totius orbis vocabularia comparativa, Band 1: XVIII: "Ю ю. Simpliciter exprimit in vocabulario jo, cum accento $\wp^{\prime}$, tamquam $\ddot{u}$ et circumflexo notatum $\wp^{\wedge}$ tamquam ju pronunciabitur." Aus technischen Gründen werden alle Akzentzeichen nicht wie im Originaldruck über den Vokalbuchstaben, sondern nach ihnen gesetzt.
} 
110. Воздухъ; 114. Глубина; 115. Высота; 118. Дира; 120. Ровъ; 121. Камень; 124. Соль; 125. Чудо;

Bd. 2: 131. Дубъ; 132. Пень; 134. Плоды; 135. Кора; 136. Корень; 137. Сукъ; 140. Жито; 141. Рожь; 142. Овесъ; 143. Виноградъ; 144. Рыба; 145. Червь; 146. Муха; 147. Звърь; 151. Рогъ; 155. Котъ; 156. Мышъ; 157. Птица; 158. Перо; 16о. Яйцо; 162. Гусь; 163. Утка; 164. Голубь; 168. Домъ; 169. Дверь; 17о. Дворъ; 173. Мъра; 177 Гвоздь; 178. Возъ; 179. Хльбъ; 188. Побъда; 194. Полъ; 196. Иго; 197. Судно; 199. Свътъ; 20о. Громъ; 208. Бъло; 220. Зло; 248. Ты; 249. Онъ; 251. Мы; 252 Вы; 253. Они; 254. Имъ; 263. Подъ; 268. Прежде; 269. Посль.

Die Zahl der völligen Übereinstimmungen ist beachtlich, aber sie läßt sich streng genommen erst dann richtig beurteilen, wenn man weiß, welche Texte der Informant oder die Redaktion hier als Repräsentanten von Kirchenslavisch angesehen haben, und geklärt ist, daß wenigstens ein solcher Text das jeweils in Frage stehende Wort enthält. Sollte in einem derartigen Text auch nur einmal die in dieser Liste schon Dobrovský aufgefallene Form ночь (statt ksl. нощь) oder das Wort мпсяцъ (statt луна) mit der Bedeutung "Mond" vorkommen (vgl. 3.4.), wäre gegen solche Eintragungen in den Vocabularia nichts einzuwenden, wohl aber, wenn man sich damals vielleicht darauf verständigt haben sollte, daß auf der Kirchenslavisch-Zeile nur typisch kirchenslavisches Wortgut wie z. B. Wörter mit Sonderbedeutungen im Sprachgebrauch der Bibel erscheinen darf. Über die Zugehörigkeit eines Worts zu dieser besonders charakteristischen Lexik des kirchenslavischen Schrifttums kann man selbst heute nicht ohne weiteres entscheiden, weil es ein repräsentatives großen Kirchenslavisch-Wörterbuch etwa für alle Belege des Cerkovnyj krug oder eine entsprechende Datenbank noch nicht gibt. Umgekehrt zeigen russische Vorgaben wie Nr. 66. ВЛАСТЬ, Nr. 143. ВИНОГРАДЪ oder Nr. 268. ПРЕЖДЕ anschaulich durch ihre nicht-ostslavische Form, daß beim "Übersetzen" diese Kirchenslavismen des Russischen gewissermaßen an ihren Ausgangspunkt zurückkehren, und wer z. B. schon einmal die Dogmatik des Johannes von Damaskus in einer der kirchenslavischen Übersetzungen gelesen hat, erinnert sich möglicherweise daran, daß die in den Vocabularia unter Nr. 48-52 so wunderbar zwischen Russisch und Kirchenslavisch übereinstimmend genannten Bezeichnungen der fünf Sinne des Menschen слухъ, зрпніе, вкусъ, обоняніе, осязаніе eine kirchenslavische Belegtradition haben, die mit erstaunlich geringen Modifikationen bis ins Bogoslovie des bulgarischen Exarchen Johannes aus dem 10. Jh. zurückreicht. ${ }^{16}$ Eine erste Erklärung für die große Zahl der

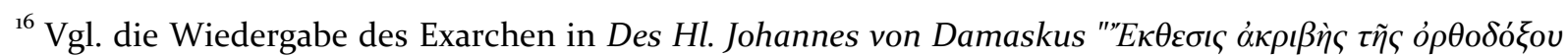

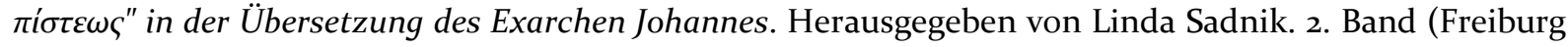
i. Br.: U. W. Weiher, 1981), 70, mit видъ, слухъ, обоняние, въкусъ, осязание; diejenige der südslavischen Übersetzung des 14. Jh. in Die Dogmatik des Johannes von Damaskus in der kirchenslavischen Übersetzung des 14. Jahrhunderts. Herausgegeben von Eckhard Weiher unter Mitarbeit von Felix Keller und Heinz Miklas (Freiburg i. Br.: U. W. Weiher, 1987), 198, mit видъние, слышание, обоняние, вькушение, осезание; diejenige der Kurbskij-Übersetzung des 16. Jh. in Die Dogmatik des Johannes von Damaskus in der Übersetzung des Fürsten Andrej M. Kurbskij (1528-1583). Herausgegeben von Juliane Besters Dilger unter Mitarbeit von Eckhard Weiher, Felix Keller und Heinz Miklas (Freiburg i. Br.: Weiher, 1995), 192-194, mit видпние, слухъ, обоняние, вкушение, осязание; oder Aufzählungen des frühen 18. Jh. im Slovar' russkogo jazyka XVIII veka. Vypusk 1-20 (Leningrad bzw. Sankt-Peterburg: Izdatel’stvo "Nauka," Leningradskoe otdelenie, bzw. "Nauka," 1984-2013) 3:192, mit зрпние, слышание,
} 
hier vom Bearbeiter für möglich gehaltenen Wortschatzgemeinsamkeiten zwischen diesen zwei Sprachen könnte also darin zu suchen sein, daß dieser sich der großen Schnittmenge der beiden Wortschätze bewußt war und entsprechend großzügig mit Übereinstimmungen gerechnet hat.

3.1.2. Die kirchenslavische Wortform stimmt mit der russischen völlig überein, ist aber zusätzlich akzentuiert:

Bd. 1: 90. Ве'черъ; 94. Зима'; 98. Вода'; 106. Гора';

Bd. 2: 176. По'ясъ; 180. Вино'; 198. Ки'тъ; 207. Ма'ло; 209. Че'рно; 211. Зеле'но; 212. ó 'стро [sic!]; 214. Ле'гокъ; 225. Жи'во; 250. Она'.

Da unter Nr. 198 sogar ein Monosyllabon den Akzent erhalten hat, darf man vermuten, daß diese 14 Akzentuierungen ohne besondere Absicht eingetragen worden sind und die Inkonsequenz ihres Auftretens ebenso wie die falsche Schreibung von Wörtern auf hastige Arbeit der Redaktion zurückzuführen ist.

3.1.3. Die kirchenslavische Wortform gehört zu demselben slavischen Etymon wie die russische, weicht aber durch divergente Lautentwicklung bzw. unerschiedliche Stammform oder Endung von ihr ab:

Bd. 1: 2. НЕБО: Небеса; 4. МАТЬ: Матерь; 15. ЛЮДИ: Лю^дїе; 16. ГОЛОВА: Глава; 23. УХО: Ушесо; 25. ВОЛОСЪ: Власъ; 53. ГОЛОСЪ: Гласъ; 60. ЛЮБОВЬ: Лю^бы; 65. МОЧЬ: Мощь; 93. ОСЕНЬ: Есень; 107. БЕРЕГЬ: Брегъ; 112. ОГОНЬ: Огнь; 122. ЗОЛОТО: ЗЛато; 123. СЕРЕБРО: Сребро; 128: ДЕРЕВО: Древо;

Bd. 2: 133. ЛИСТЬИ: Листья; 149. КОРОВА: Крава; 153. СВИНЬЯ: Свинїя; 166. БОРОНА: Брана; 171. ГОРОДъ: Градъ; 203. ЗДОРОВЪ: Здравъ; 219. БЛАГъ: Благїй; 229. ПЂТЬ: Пђти; 237. РЂЗАТЬ; РБзати; 238. СЪЯТЬ: СЪяти; 256. ЧЂМъ: Чимъ.

Unter diesen 26 Paaren befinden sich viele mit den bekannten Merkmalen der formalen Unterschiede zwischen kirchenslavischem und russischem Wortgut, etwa Beispiele für die Opposition von südslavischer Metathesen- und ostslavischer Polnoglasie-Form oder von Infinitiven auf -mu und -mb. Während in solchen Fällen gewisse Rückschlüsse von der russischen auf die kirchenslavische Form noch denkbar sind, dürfte das bei anderen Gegensätzen in dieser Gruppe nicht so leicht möglich gewesen sein, vgl. nicht so Alltäglich-Geläufiges wie unter $\mathrm{Nr}$. 23. Ушесо, Nr. 133. ЛИСТЬИ oder den Gegensatz von Kurz- und Langform bei Nr. 219. БЛАГЪ: Благїй.

3.1.4. Die kirchenslavische Wortform gehört wie die unter 3.1.3. genannten zu demselben Etymon wie die russische, ist aber zusätzlich akzentuiert:

вкушение, обоняние и ощущение bei Tatiščev und aus der zweiten Jahrhunderthälfte im Slovar' russkogo jazyka XVIII veka 16: 41-42, mit видпние, слух, обоняние, вкус и осязание bei Kozel'skij und слух, обоняние, вкус, осязание, взор bei Radiščev. 
Bd. 1:31. БОРОДА: Брада'; 47. МОЛОКО: Млеко';

Bd. 2: 228. ПИТЬ: Пи'ти; 231 СПАТЬ: Спа'ти; 235. НОСИТЬ: Носи'ти; 236. ВОЗИТЬ: Вози'ти; 241. ЛИТЬ: Ли'ти; 242. ВАРИТИ: Вари'ти.

Warum gerade die hier genannten 6 Infinitive sowie Брада' und Млеко' des zusätzlichen Akzents bedurft haben, bleibt das Geheimnis der Redaktion; in der vorigen Gruppe scheinen die kirchenslavischen Infinitive unter Nr. 229, 237 und 238 wohl deshalb nicht akzentuiert zu sein, weil der Buchstabe $\langle\mathrm{b}\rangle$ in diesem Druck, soweit zu erkennen ist, keine akzentuierte Type aufweist.

3.1.5. Das kirchenslavische Wort gehört zu einem anderen slavischen Etymon als das russische oder enthält ein deutlicher Abstand schaffendes anderes Ableitungselement; belegt wird das von insgesamt 47 Wortartikeln:

Bd. 1: 8. СЕСТРА: Сестреница;12. МАЛЬЧИКЪ: Отрокъ; 13. ДИТЯ: Отроча; 20 ГЛАС̆ъ: Око; 22. РЕСНИЦЫ: Въжди; 24. ЛОБъ: Чело; 26. ЩОКИ: Ланиты; 27. РОТЪ: Уста; 28. ГОРЛО: Гортань; 33. ПЛЕЧО: Рамо; 36. ПАЛЬЦЫ: Персты; 37. НОГТИ: Пазнокти; 39. СПИНА: Хребетъ; 55. КРИКЪ: Кличъ; 57. ВОПЛЬ: Плищъ; 58. СЛОВО: Глаголъ; 63. РАБОТА: Дълательство; 67. БРАКЪ: Женидба; 71. СМЕРТЬ: Кончина; 74. ШАРЪ: Клубъ; 95. ГОДЪ: Льто; 103. ГЛИНА: Бренїе; 105. ГРЯЗЬ: Бренїе; 113. ЖАРЪ: Зной; 116. ШИРИНА: Широта; 117. ДЛИНА: Долгота; 126. ЛЂСЪ: Дубрава; 129. КОЛЪ: Дреколье;

Вd. 2: 150. БАРАНЪ: Овенъ; 154. СОБАКА: Песъ; 159. ПЪТЕЛЬ: Куръ; 161. КУРИЦА: Кокошъ; 172. ОЧАГЪ: Горнило; 187. БЪДА: Горе; 191. ЛЬНЬ: Лъность; 193. РОДИНЫ: Рождество; 204. ВЫСОКО: Горђ; 221. ДУРНО: Злъ; 222. ХУДО: Злъ; 224. ТИХО: Косно; 226. РАДЪ: Радостенъ; 245. СТОЙ: Стани; 247. Я: Азъ; 258. ДА: Ей; 26о. ГДБ: Идъже; 261 ЗДБСЬ: Здъ; 266. КОГДА: Егда.

Spätestens mit dieser Gruppe beginnt derjenige Bereich der Lexik, in dem Rückschlüsse von der russischen Form auf die kirchenslavische kaum erfolgversprechend sind, weil die Unterschiede sich nicht wiederholen.

3.1.6. Das kirchenslavische Wort gehört in 9 Fällen zu einem anderen slavischen Etymon als das russische, ist aber zusätzlich akzentuiert:

Bd. 1: 32. ШЕЯ: Вы'я;

Bd. 2: 138. ПОЛЕ: Село'; 139. ЛУГЪ: Съножа'тъ; 165. СОХА: Ра'ло; 195. ПАШНЯ: Ни'ва; 205. НИЗКО: До'лу; 213. СЫРО: Вла'жно; 239. ПАХАТЬ: Ора'ти; 273. ВОТъ: Се'.

Auch hier hat mit Nr. 273 ein Monosyllabon einen Akzent erhalten. 
3.1.7. Bei 39 russischen Lemmata bilden auf der Kirchenslavisch-Zeile mehrere Wörter die Entsprechung eines russischen. Dabei wird z. T. das vorgegebene russische Wort wiederholt, und auch hier gibt es manche zusätzlich akzentuierte Form (unter Nr. 111 sogar eine mit zwei Akzenten):

Bd. 1: 11. ДЂВА: Дьва, Отроковица; 17. ЛИЦО: Лице, Ликъ; 38. БРЮХО: Чрево, Утроба; 56. ШУМъ: Шумъ, Шукотъ; 61. БОЛЬ: Болъзнь, Недугъ; 64. СИЛА: Кръпость, Сила; 68. ЖИЗНЬ: Житіе, Животъ; 69. РОСТъ: Ни'кнути, Нигати; 72. СТУЖА: Хладъ, Хладота'; 96. ВРЕМЯ: Время, Пора'; 104. ПЫЛЬ: Прахъ, Персть; 109. ДОЛИНА: Юдолъ, Удолї; 111. ПАРЪ: Па'ра'; 119. ЯМА: Вертевъ, Язвина; 127. ТРАВА: Былїе, Злакъ; 1зо. ЗЕЛЕНЬ: Злакъ, Зелїе;

Bd. 2: 148. БЫКЪ: Волъ, Говядо; 167. МЕЖА: Предълъ, Межда'; 174. КАДь: Дехва, Спудъ; 175. ТОПОРЪ: Съкира, Съчиво; 181. ЯСТВЫ: Снъдь, Ястїе, Бражна; 185. БРАНЬ: Кото'ра, Сваръ; 186. ДРАКА: Сраженїе, Бой; 189. ВОЙН: Рать, Брань, Ратоборство; 190. ВОИНъ: Ратникъ, Ратоборецъ, Боинъ; 192. ЛАДъ: Согласїе, Миръ; 201. МОЛОДъ: Младъ, Юнъ; 202. СТАРЪ: ВЪтхъ, Древенъ; 206. ВЕЛИКО: Вели'ко, Гольмо; 210. КРАСНО: Че'рмно, Червлено; 215. ТОЛСТъ: Грубъ, Дебелъ; 216. ДОБРО: До'бро, Благо; 217. ХОРОШО: Добрђ, Блазђ; 218. ЛЂПО: ЛЪпотно, Благольпотно; 223. СКОРО: Быстро, Скоро, Бо'рзо, Абї; 255. ЧТО: Что, Яко; 259. НБТЪ: Ни, Нњсть; 262. ТАМъ: Тамо, Овамо, Онде, Онамо; 27о. КАКъ: Какъ, Яко.

3.2. In den 19 komplexen Lemmata des zweiten Bands stehen mehrere russische Wörter über dem Artikel. In den ersten zwei Fällen sind beide Wörter in Versalien gesetzt; danach wird nur das erste so hervorgehoben, und die weiteren Angaben folgen in Klammern und in gewöhnlicher Schrift. In der 1789 dem zweiten Band vorangestellten Gesamtliste wird nur jeweils das erste dieser Wörter aufgenommen:

Bd. 2: 152. КОНЬ, ЛОШАДЬ: Конь; 182. ТАТЬ, ВОРЬ: Тать; 183. ЛАТЫ, (древ. доспьхъ): броня; 184. СТОРОЖЪ, (караулъ): Стражъ; 227. ЯСТИ (Бсть, Кушать): Ясти; 230. БИТЬ (Ударить): Разити, Ударяти, Бити; 232. ЛЕЧЬ (Ложится, Лежать): Лещи, Возлещи; 233. ВЗЯТь (Брать, Имать, Принять): Яти, Пояти; 234. ЛЮ^БИТЬ (Миловать): Лю^бити; 240. СКРЫТЬ (Спрятать, Таить): Сокрыти; 243. ЕСТЬ (Бываетъ): Есть; 244. ДАЙ (Давай): Даждъ; 246. ИДИ (Пади, Ступай): Иди, Гряди, Шествуй, 257. КЂМЪ (Кто): Кто, Књмъ; 264. НАДЪ (На): Надъ; 265. ВО (Въ): Во; 267. ТЕПЕРЬ (Нынъ): Нынъ; 271. БЕЗЪ (Кромъ): Безъ; 272. ИЛИ (Либо): Или.

Die Erweiterungen der Lemmata sind schwer zu erklären, zumal in Nr. 227 eine kirchenslavische Form die zwei in der Klammer folgenden russischen dominiert. In mehreren Fällen könnte es sich um Angabe von Synonymen handeln, etwa bei Nr. 152, 182, 184, 230 u. a., aber die Angaben bei Nr. 183, 234 oder 265 wird man schwerlich als Synonympaare ansehen, in Nr. 257 liegen sogar nur verschiedene Flexionsformen ein und desselben Pronomens vor, und bei den Verben geht es z.T. um Aspektunterschiede. Besonders merkwürdig ist Nr. 232, weil zwar лечь und ложиться "sich legen" ein Aspektpaar bilden, лежать "liegen" aber zweifellos eine Bedeutung 
hat, die nicht zu ihnen paßt und aus russischer Sicht einen eigenen Artikel erhalten müßte. Darüber hinaus fällt auf, daß in der eingangs abgedruckten Gesamtliste russ. лечь "sich legen" auf fragwürdige Weise mit lat. jacere, also "liegen," verbunden wird" und Adelung den Artikel Nr. 232 gleichfalls mit der Bedeutungsangabe "Liegen" führt. ${ }^{18}$ Zusammenbringen lassen sich die verschiedenen Bedeutungen dieser Verben vielleicht über das französische Verb coucher, das nicht nur transitiv als "legen," sondern auch intransitiv als "liegen" vorkommt und zudem reflexiv als se coucher "sich legen" verwendet wird. ${ }^{19}$ Über eine solche französische Zwischenstufe könnte man auch das aus russischer Sicht eigenartige - um nicht zu sagen: abwegige - Lemma Nr. 264 НАДъ (На) erklären: hier hat möglicherweise jemand an die französische Präposition sur gedacht, in der die Bedeutungen "über" und "auf" leicht zu verbinden sind. ${ }^{20}$ Der naheliegenden Frage, ob in den russischen Lemmata der Zarin nicht noch mehr heimliches Französisch steckt, kann hier nicht mehr nachgegangen werden, doch sollte man bei der weiteren Beschäftigung mit den Vocabularia daran denken.

3.3. Die Gemeinsamkeiten (“2,” “4," “5," “6," “9,” “10,” und “10o”) und Unterschiede (“1,” "3," “7," "8," “1000”) zwischen den hier aufgeführten zwölf russischen und kirchenslavischen Grundzahlen sind wohl so bekannt und übersichtlich, daß man sie nicht mehr kommentieren muß:

Bd.2 (S. 472-491): 1: Одинъ / Единъ; 2: Два / Два; 3: Три / Трїе; 4: Четыре / Четыре; 5: Пять / Пять; 6: Шесть / Шесть; 7: Семъ / Седмь; 8: Восемь / Осмь; 9: Девять / Девять; 10: Десять / Десять; 100: Сто / Сто; 1000: Тысяча / Тй' сяща.

3.4. Insgesamt gesehen hat der anonyme Bearbeiter der Kirchenslavisch-Zeile neben vielen selbst aus heutiger Sicht plausiblen lexikalischen Übereinstimmungen zwischen Russisch und Kirchenslavisch auch nicht wenige heute noch einleuchtende Unterschiede zwischen ihnen benannt. Freilich gilt diese Ausage mit der Einschränkung, daß wir nicht wissen, in welcher begrifflichen Extension die Sprachbezeichnung “славянский” in den Vocabularia von ihm verstanden worden ist. Bezeichnenderweise hat schon Dobrovský 1796 gewisse Zweifel geäußert, ob wirklich alle Eintragungen in der Kirchenslavisch-Zeile auch als kirchenslavisch anzuerkennen seien, nämlich in den ersten drei seiner insgesamt, soweit ich sehe, lediglich fünf das Kirchenslavische erwähnenden Artikelkommentare:

1) Unter Nr. 71. СМЕРТЬ hat er zur Eintragung Кончина gefragt: "Warum hier im Slawenischen N. 1. končina, d. i. Ende, finis, das freylich auch vom Lebensende gesagt werden kann, stehe und nicht lieber smrt', wer soll dieß errathen?"21

\footnotetext{
${ }^{17}$ Linguarum totius orbis vocabularia comparativa, Band 2: XIII.

${ }^{18}$ Adelung, Catherinens der Grossen Verdienste um die Vergleichende Sprachenkunde, 75.

${ }^{19}$ In der französischen Zeile des Artikels 232 liest man als Übersetzung nur Се-Кушерь.

${ }^{20}$ In der französischen Zeile des Artikels 264 liest man dagegen $С_{ю}$ ' $р$ ь, Дессю' , also die Präposition sur

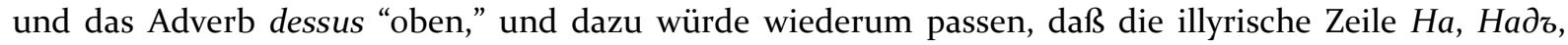
Гори und die kleinrussische Надъ, Выше vorschlagen, d. h. mit Гори bzw. Bыше gleichfalls ein Adverb hinzufügen.

${ }^{21}$ Dobrovský, Rossica. Srovnání ruské a české řeči, 34.
} 
2) Unter Nr. 76. МБСЯЦЪ hat er zu Мпсяцъ auf der ersten Zeile angemerkt: "Im Slawonischen sollte hier luna stehen, weil dieß Wort in der Bibel, deren sich die Russen bedienen, $\mathrm{zu}$ finden ist, und eigentlich den Mond bedeutet."22

3) Unter Nr. 88. НОЧЬ hat er die Eintragung Ночь auf der Kirchenslavisch-Zeile abgelehnt: "Im altslawonischen nossč (sprich Noschtsch,) nicht noč, denn dieses ist Russisch und illyrisch nach der jetzigen Aussprache." 23

4) Unter Nr. 171. ГОРОДъ hat er die Eintragung von Градъ auf der zweiten Zeile, im Slovakischen, aus semantischen Gründen verworfen: "Slow. mesto, nicht hrad. Denn dieß ist eine Burg, ein Schloß, weicht also in der Bedeutung vom Slawonischen grad, Russisch gorod, ab." ${ }^{24}$

5) Unter den abschließend in einer gemeinsamen Tabelle aufgeführten Zahlwörtern hat er das auf der slovakischen Zeile für "1" eingesetzte Единъ als kirchenslavisch zurückgewiesen: "Gedin beym Slowakischen ist Slawonisch." 25 Dem von Dobrovský als Informant vermuteten Rusnjaken war anscheinend in seinem russisch geprägten Wortschatz auch Kirchenslavisches nicht ganz fremd.

Am interessantesten sind zweifellos Dobrovskýs Bemerkungen zu СМЕРТЬ und МЂСЯЦЪ, denn er greift bei diesen Artikeln semantische Probleme auf, die das Lexikon vernachlässigt hat: кончина sei kein wirkliches Äquivalent zu смерть, weil es nur in übertragenem Sinne "Lebensende" bedeuten könne, und мпсяцъ habe im Kirchenslavisch der Bibel nicht die Bedeutung "Mond," sondern "Monat." Anders als die Vocabularia gibt er zudem mit dem Hinweis auf die Bibel ein klares Kriterium für die Beurteilung von Kirchenslavizität an und lehnt aus formalen Gründen das russische ночь wohl zu Recht als kirchenslavisch ab. Dobrovský konnte so argumentieren, weil er als Theologe und Philologe anerkanntermaßen schon damals ein guter Kenner des kirchenslavischen Bibeltextes war, nicht zuletzt aber auch deshalb, weil er auf seiner Reise nach Rußland die in der ersten Hälfte des 18. Jh. dort entstandenen Konkordanzen zum kirchenslavischen Psalter und zum Neuen Testament ${ }^{26}$ kennengelernt hatte und zwei dieser Bände sogar erwerben konnte. ${ }^{27}$ Sein klares Urteil könnte sich z. B. auf die Einzelnachweise der erstmals 1733 erschienenen und 1762 noch einmal gedruckten Konkordanz zum Text der Evangelien und der Apostelgeschichte des Ivan Il'inskij (? - 1737) stützen. ${ }^{28}$ Aus den von Dobrovský in diesen drei Artikeln exemplarisch offengelegten und mit Unverständnis quittierten Defiziten ergibt sich aber wohl auch, daß der mit der Kirchenslavisch-Zeile betraute Petersburger Informant zumindest an diesen Stellen offenbar keinen Gebrauch von

\footnotetext{
${ }^{22}$ Dobrovský, Rossica. Srovnání ruské a české řeči, 35.

${ }^{23}$ Ibid., 37.

${ }^{24}$ Ibid., 41.

${ }^{25}$ Ibid., 46

${ }^{26}$ Helmut Keipert, "Zur Geschichte der kirchenslavischen Bibelkonkordanzen," in Petr Andreevič Gil'tebrandt, Spravočnyj i objasnitel'nyj slovar' k Novomu Zavetu. Nachdruck [der Ausgabe Petrograd 1882-1885] besorgt von Helmut Keipert und František Václav Mareš. Bd. I-VI (München: Verlag Otto Sagner, 1988-1989), I: 7-19, hier 10-14.

${ }^{27}$ Korrespondence Josefa Dobrovského, 275.

${ }^{28}$ Vgl. Ivan Ivanovič Il'inskij, Simfonia ili soglasie na svjaščennoe četveroevangelie i dejanija svjatych apostol [...] (Moskva, 1733), 109v zu кончина und 205v zu смерть, $115 \mathrm{~V}$ zu луна und $127 \mathrm{zu}$ мпсяцъ sowie $140 \mathrm{zu}$ нощь.
} 
Il'inskijs Simfonija, von der Psalter-Konkordanz des Antioch Kantemir (1728) oder von Andrej Bogdanovs Konkordanz zu den Apostelbriefen und zur Offenbarung (1737) gemacht hat, also von den lexikographisch vollständigsten Nachschlagemöglichkeiten, die es damals für biblisches Kirchenslavisch gab. Anscheinend ist diesem Mitarbeiter der Vocabularia nicht einmal bekannt gewesen, daß 1758 Michajlo Lomonosov in seinem auch heute noch vielbeachteten Predislovie o pol'ze knig cerkovnych $v$ rossijskom jazyke das Übereinstimmende und das Nichtübereinstimmende zwischen Kirchenslavisch und Russisch in fünf Wortklassen mit Beispielen aus der PsalterKonkordanz Kantemirs veranschaulicht hat. ${ }^{29}$ Einen besonderen Kenner der Probleme des Kirchenslavischen sollte man in ihm also kaum vermuten, aber es ist nicht einmal auszuschließen, daß Dobrovský ihn zumindest dem Namen nach gekannt hat, denn in Petersburg ist er 1792 auch Pallas begegnet, und es fällt auf, daß er deutlichere Kritik an der unzulänglichen Behandlung der russischen Kirchensprache, wie er sie von einem in Rußland entstandenen Wörterbuch offenbar nicht erwartet hatte, ${ }^{30} \mathrm{zu}$ vermeiden sucht. So ist z. B. kaum vorstellbar, daß er bei seiner gründlichen Durchsicht unter Nr. 69. РОСТЪ die als kirchenslavische Entsprechung eingetragenen

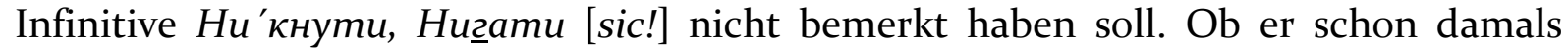
gewußt hat, daß es im kirchenslavischen Schrifttum das südslavisch-oppositive pacmъ gibt, das hier hätte eingesetzt werden können, sei dahingestellt. ${ }^{31}$ Selbst ohne dieses Wissen konnte er aber schwerlich mit diesen zwei Verbformen einverstanden gewesen sein, die hier statt eines Verbalsubstantivs als Äquivalente des russischen Lemmas vorgeschlagen werden, denn kurz zuvor hatte er unter $\mathrm{Nr}$. 48. СЛУХЬ in einer Anmerkung der Redaktion gelesen, daß vielen Völkern (etwa Finnen, Tataren, Samojeden) für die Bezeichnung der fünf Sinne ein Substantiv fehle und die betreffenden Übersetzer sich deshalb mit entsprechenden Verben hätten behelfen müssen. Auf diese ihn überhaupt nicht befriedigende Erklärung hat er in seinem Kommentar zu Nr. 52. ОСЯЗАНIE sehr entschieden reagiert: für den Fall, daß zu

\footnotetext{
${ }^{29}$ Vgl. Helmut Keipert, "Die knigi cerkovnye in Lomonosovs 'Predislovie o pol'ze knig cerkovnych v rossijskom jazyke'," Zeitschrift für Slavische Philologie 54:1 (1994), 21-37, bzw. idem.,"Cerkovnye knigi v 'Predislovii o pol'ze knig cerkovnych v rossijskom jazyke' M. V. Lomonosova," Rusistika segodnja 95/4 (1995), 31-46.

${ }^{30}$ In diesem Zusammenhang ist daran zu erinnern, daß Dobrovský 1792 noch von Petersburg aus sehr entäuscht an Durich geschrieben hat, daß sich dort kein Russe für dessen in Vorbereitung befindliche Bibliotheca slavica antiquissimae dialecti communis et ecclesiasticae universae Slavorum gentis interessieren wollte: "Quaeris postremum ex me, quid eruditiores Russi sentiant de opere, quod paras. Ut verum dicam, non potui altero mense urbem percursitans eruditos Russos istarum rerum amantes reperire. Interim spe delector me reperturum Mosquae viros, qui slavonicarum antiquitatum curiosiores sint. [...] Russi nativi nihil nisi vulgarem suam legunt atque scribunt - minus curiosi aliarum rerum romanenses historias vertunt et vendunt, solidiora fere fastidiunt." ["Schließlich fragst du mich, was die gebildeteren Russen von dem Werk halten, das du vorbereitest. Um die Wahrheit zu sagen, ich laufe schon den zweiten Monat durch die Stadt und habe doch keine gebildeten Russen finden können, die diese Dinge schätzen. Einstweilen hoffe ich in Moskau Männer zu finden, die sich mehr für die slavischen Altertümer interessieren. Die geborenen Russen lesen und schreiben nur ihre Volkssprache sind weniger interessiert an anderen Dingen - übersetzen und verkaufen Romane - Substantielleres verachten sie fast."] Auch später in Moskau ist sein Eindruck nicht sehr viel besser gewesen: "Eheu! in desertis tu cultos homines quaeris!" [“Ach! du suchst in der Wüste gebildete Menschen!"]. Dobrovský, Rossica. Srovnání ruské a české řeči, 6 und Korrespondence Josefa Dobrovského, 261-262 und 319.

${ }^{31}$ Vgl. Joseph Dobrowsky, Institutiones linguae Slavicae dialecti veteris, quae quum apud Russos, Serbos aliosque ritus Graeci, tum apud Dalmatas Glagolitas ritus Latini Slavos in libris sacris obtinet (Vindobonae: Antonius Schmid, 1822), 127.
} 
einem solchen Verb kein davon abgeleitetes Substantiv zu finden sei, hat er ausgehend vom Beispiel eines ihm künstlich erscheinenden “Äquivalents” im Ungarischen (!) empfohlen, es solle "der ehrliche Übersetzer [...] [1]ieber gestehen, daß für diesen oder jenen Begriff kein bestimmtes Wort in seiner Sprache vorhanden sey, als erst jetzt aus Noth ein neues schmieden." ${ }^{2}$ Daß er sich damals nicht ebenso deutlich mit grundsätzlicher Kritik am Kirchenslavischen unter Nr. 48 geäußert hat, könnte mit seinem Plan einer sorgfältigen Verbesserung des slavischen Teils der Vocabularia zusammenhängen, den er auch 1796 noch der Vsevysočajšaja osoba in Petersburg vorzulegen gedachte. ${ }^{33}$ Der Tod der Zarin im November 1796 dürfte der Grund sein, weshalb dieses Vorhaben später nicht mehr mit gleicher Energie fortgeführt worden ist.

\section{Sind bei der Äquivalentsuche auch Lexika herangezogen worden?}

Viktor Markovič Živov, dessen Andenken dieser Beitrag gewidmet ist, hat uns noch im Rahmen der Diglossie-Theorie erläutert, wie das Kirchenslavische bei den Ostslaven in alter Zeit gelernt worden ist, nämlich ohne Grammatiken und Lexika vor allem durch an der Muttersprache (!) orientierte Umrechnungsregeln ("pravila peresčeta") für Orthographie, Orthoepie und Morphologie, wobei vor allem das Buchstabieren nach Silben bzw. Konsonant-Vokal-Kombinationen eine Rolle gespielt hat. ${ }^{34}$ Während solche Regeln für das beim Umgang mit kirchenslavischen Texten damals im Vordergrund stehende richtige Lesen im Gottesdienst und das korrekte Abschreiben von Texten im Skriptorium ausreichten, waren für das viel seltener vorkommende Abfassen eigener Werke in dieser Sprache (oder das Übersetzen in sieH.K.) Wortschatz- und Syntaxkenntnisse erforderlich, die nur durch das Auswendiglernen von eventuell vorhandenen Wortlisten bzw. durch die Imitation geeigneter Textmuster erworben werden konnten, und deshalb waren auf diesen beiden Gebieten auch die Grenzen des Normativen viel weniger genau bestimmt:

“Простые правила такого рода естественно формулировались для орфографических и морфологических явлений, но были малодоступны в лексике и синтаксисе: в лексике это предполагало бы заучивание списков отдельных слов; книжный же синтаксис резко отличался от синтаксиса любых славянских диалектов, что лишало основания самый процесс адаптации на данном уровне. [...] Задача орфографической и морфологической унификации возникала при переписке стандартных текстов, имевшей массовый характер. Задачи же синтаксической и лексической нормализации при переписке практически не возникало. Такая задача становилась актуальной лишь при создании новых книжных текстов, а это было делом отдельных книжников, выполнявшимся ими в меру их индивидуального мастерства. [...] При создании оригинальных

\footnotetext{
32 Dobrovský, Rossica. Srovnání ruské a české řeči, 33.

${ }^{33}$ Keipert, "Die Pallas-Redaktion der Petersburger Vocabularia comparativa und ihre Bedeutung für die Entwicklung der slavischen Sprachwissenschaft," 135-137.

34 Vgl. zu den Möglichkeiten einer Rekonstruktion dieses "peresčet” auch Natal’ja Nikolaevna Zapol'skaja, Istorija russkogo literaturnogo jazyka. Metodičeskie ukazanija dlja studentov filologičeskich fakul'tetov gosudarstvennych universitetov (Moskva: Izdatel'stvo Moskovskogo universiteta, 1991), 4-19.
} 
текстов руководством служили не правила, не грамматика, а образцы, задававшиеся корпусом постоянно переписываемых текстов." 35

Die von Katharina II. gewünschte Umsetzung der russischen Wortliste ins Kirchenslavische bedeutete praktisch die Schaffung einer Abfolge von Vokabeln, für deren Zusammensetzung es im kirchenslavischen Schrifttum auch im 18. Jh. kein direktes Textvorbild gegeben hat, das man hätte imitieren können, und für deren Erstellung auch ein hinreichend umfangreiches zweisprachig russischkirchenslavisches Wörterbuch fehlte, das einen Russen aus der Sicht seiner Muttersprache über die im Kirchenslavischen jeweils bestehenden Ausdrucksmöglichkeiten hätte unterrichten können, ${ }^{36}$ denn es gab (und gibt bis heute) nicht einmal ein annähernd vollständiges kirchenslavisch-russisches Lexikon, das bei der Verifizierung von vielleicht erwogenen Äquivalenten eine Hilfe (gewesen) wäre. ${ }^{37}$ Bei der Ermittlung der kirchenslavisch-russischen Wortpaare für die Vocabularia war also im Prinzip noch immer ähnlich wie im Mittelalter vor allem das vom Russischen zum Kirchenslavischen führende Assoziationsvermögen des Informanten gefordert. Zwar lagen im 18. Jh. schon einige Lexika vor, die kirchenslavische Wörter für Russen erklärten und wenigstens in einzelnen Fällen die Suche nach Entsprechungen unterstützen konnten, wenn man die damit verbundenen Umwege und auch das häufig vergebliche Nachschlagen nicht scheute, doch haben die zwei von mir gemachten Proben aufs Exempel trotz mancher punktueller Parallelen keine sicheren Indizien ergeben, daß die betreffenden Werke für die Vocabularia tatsächlich auch genutzt worden sind. ${ }^{38}$

\footnotetext{
${ }^{35}$ Viktor Markovič Živov, "Rol' russkogo cerkovnoslavjanskogo v istorii slavjanskich literaturnych jazykov," in Aktual'nye problemy slavjanskogo jazykoznanija. Pod redakciej Klavdii Vasil'evny Gorškovoj, Georgija Aleksandroviča Chaburgaeva (Moskva: Izdatel'stvo Moskovskogo universiteta, 1988), 49-98, hier 50-51.

${ }^{36}$ Noch aus dem 17. Jh. kennen wir heute unter dem Titel Synonima slavenorosskaja ein im weiteren Sinne ostslavisch-kirchenslavisches Lexikon, das vor allem durch Umkehrung von Artikeln des Leksikon slavenorosskij des Pamvo Berynda (Kiev 1627) entstanden ist, doch wurde die jetzt in Kiev aufbewahrte Handschrift damals nicht gedruckt, vgl. die Edition bei Vasyl' Vasyl'ovyč Nimčuk, Leksys Lavrentija Zyzanija. Synonima slavenorosskaja. Pidhotovka tekstiv pam'jatok i vstupni statti V. V. Nimčuka (Kyjiv: Vydavnictvo "Naukova dumka," 1964), 91-172.

37 Vgl. immerhin die Vollständigkeit anstrebenden Konkordanzen zum kirchenslavischen Neuen Testament und zum Psalter bei Gil'tebrandt, Spravočnyj i objasnitel'nyj slovar' k Novomu Zavetu bzw. Petr Andreevič Gil'tebrandt, Spravočnyj i ob-jasnitel'nyj slovar' k Psaltiri. Nachdruck der Ausgabe St. Petersburg 1898 mit einer Eunleitung von Helmut Keipert (München: Verlag Otto Sagner, 1993) sowie das 26000 Wortartikel zu den russischen Kirchendrucken umfassende Lexikon von Bončev mit bulgarischer Bedeutungsangabe. Vgl. Arch. Atanasij Bončev, Rečnik na cărkovnoslavjanskija ezik. Naučen redaktor Borjana Christova. Tom I-II (Sofija: Narodna biblioteka "Sv. Sv. Kiril i Metodij," 20022012).

${ }^{38}$ Genauer vergleichen könnte man die Belege der Vocabularia z. B. auch noch mit den schon erwahnten Kirchenslavismen im Slovar' Akademii Rossijskoj (vgl. oben Anm. 11) oder den 378 Wörtern, die Biržakova im 1775 gedruckten Pol'skij obščij slovar' i biblejnyj des Kiriak Kondratovič mit der Markierung "sl." nachweist. Vgl. Elena Ėduardovna Biržakova, "Otraženie funkcional'no-stilističeskoj differenciacii russkoj leksiki v dvujazyčnych slovarjach XVIII v.," in Funkcional'nye i social'nye raznovidnosti russkogo literaturnogo jazyka XVIII v. Sbornik naučnych trudov. Otvetstvennyj redaktor Vera Viktorovna Zamkova (Leningrad: "Nauka," Leningradskoe otdelenie, 1984), 133-146, hier 136; Valentin Pavlovič Vomperskij, Slovari XVIII veka (Moskva: Nauka, 1986), 50.
} 
4.1. Zeitlich den Vocabularia am nächsten steht dabei der erstmals 1773 in Moskau gedruckte und 1776 und 1779 mit zwei weiteren Bänden ergänzte Cerkovnyj slovar' des Petr Alekseevič Alekseev (1731-1801) ${ }^{39}$ und dieses Werk sollte der Petersburger Arbeitsgruppe der Zarin auch ohne weiteres zugänglich gewesen sein, sofern sie es heranziehen wollte. Alekseevs Lexikon mit dem vollständigen Titel Cerkovnyj slovar', ili Istolkovanie rečenij slavenskich drevnich, takož inojazyčnych bez perevoda položennych $v$ Svjaščennom pisanii i drugich cerkovnych knigach sočinennyj ist bisher vor allem als Versuch eines enzyklopädischen Wörterbuchs, als wichtige Vorarbeit für den Slovar' Akademii Rossijskoj und als Beitrag zur Vermeidung unnötiger Fremdwörter im Russischen gewürdigt worden. ${ }^{40}$ Ein richtiges KirchenslavischLexikon konnte es schon deshalb nicht sein, weil es erklärtermaßen vor allem zum besseren Verständnis der Bibel beitragen und die dort vorkommenden unbekannten oder in einer vom Russischen abweichenden Bedeutung gebrauchten Wörter erläutern sollte, also in erster Linie dasjenige Wortgut $\mathrm{zu}$ berücksichtigen hatte, dessen Verwendung vom Sprachgebrauch des Russischen abwich. So gesehen wird man bei Alekseev Parallelen bestenfalls für Nicht-Übereinstimmungen zwischen kirchenslavischer und russischer Zeile in den Vocabularia erhalten können. Bei einer Stichprobe mit den oben unter 3.1.5. genannten 47 Artikeln finden sich in den drei Alekseev-Bänden immerhin 23, in denen das betreffende kirchenslavische Wort von Alekseev mit dem russischen Lemma-Wort der Vocabularia erklärt worden ist, also Explicandum und Explicans für das Pallas-Wörterbuch gewissermaßen die Plätze getauscht haben müßten, weitere fünf (hier mit Fragezeichen markiert), bei denen zumindest ähnliche russische Bedeutungsangaben gemacht werden, sowie zwei (hier mit Ausrufungszeichen markiert), die aus semantischen Gründen wohl Sonderfälle darstellen:

Bd. 1:

8. СЕСТРА: Сестреница // СЕСТРЕНИЦА, сестра, Кормч. лит. 5 (1776: 231).

? 13. ДИТЯ: Отроча // ОТРОЧА, дитя, младенецъ. Мат. 2,8 (1773: 226).

20 ГЛАСъ: Око // ОКО, просто глазъ (1773: 213).

22. РЕСНИЦЫ: ВЪжди // ВБЖДА, рясница (1773: 59).

24. ЛОБЪ: Чело // ЧЕЛО, лобъ, передняя часть главы (1773: 383).

26. ЩОКИ: Ланиты // ЛАНИТА, щека (1773: 149).

27. РОТЪ: Уста // УСТА, просто ротъ, вь писаніи берется за языкъ, за лице и за рьчь (1773: 363).

33. ПЛЕЧО: Рамо // РАМО, плечо (1773: 279).

37. НОГТИ: Пазнокти // ПАЗНОГТИ, ногти животныхъ безсловесныхъ, или копыта (1773: 229).

39. СПИНА: Хребетъ // ХРЕБЕТЪ, спина, тылъ, задъ (1773: 377).

55. КРИКЪ: Кличъ // КЛИЧЬ, т. е. крикъ (1773: 134).

\footnotetext{
${ }^{39}$ Vgl. Svodnyj katalog russkoj knigi graždanskoj pečati XVIII veka. 1725-180o. 1-5, Dopolnenija. (Moskva: Gosudarstvennaja biblioteka SSSR-“Kniga," 1962-1975), 1 (1962), 28 (Nr. 91).

${ }^{40}$ Vgl. Michail Ivanovič Suchomlinov, Istorija Rossijskoj Akademii. Vypusk pervyj (Sbornik Otdelenija russkogo jazyka i slovesnosti Imperatorskoj Akademii nauk, Tom XI, 2) (Sanktpeterburg, 1874), 280-343; Vomperskij, Slovari XVIII veka, 45-47; Grigorij Aleksandrovič Lichotkin, "Alekseev, Petr Alekseevič," in Slovar' russkich pisatelej XVIII veka (Leningrad: "Nauka," Leningradskoe otdelenie, 1988), Vypusk 1 (A-I), 28; Biržakova, “Leksikografija XVIII veka,", 74-76.
} 
? 57. ВОПЛЬ: Плищъ // [ПЛИЩъ, крикъ, шумъ (1773: 238)].

58. СЛОВО: Глаголъ // ГЛАГОЛЬ, т. е. слово, или рњчь (1773: 64).

? 63. РАБОТА: ДЬлательство // [ДЂЛАТЕЛЬСТВО, дЬйствіе, дЬланіе, мастерство (1776: 67).]

! 67. БРАКЪ: Женидба // БРАКЪ; законное мужа и жены сочетаніе, инакъ называется супружество, а иногда и женитва (1773: 32); [ЖЕНИТВА, бракосочетание, супружество, бракъ (1773: 96)].

95. ГОДъ: Льто // ЛЂТО, въ писаніи берется за цьлой годъ (1773: 158).

103. ГЛИНА: Бренї // БРЕНІЕ, глина, грязь, горшечная земля (1773: 32).

105. ГРЯЗЬ: Бренїе // БРЕНІЕ, глина, грязь, горшечная земля (1773: 32 ).

126. ЛЂСЪ: Дубрава // ДУБРАВА и ДУБРОВА, частой льсъ и густой (1776: 64).

? 129. КОЛЪ: Дреколье // ДРЕКОЛІЕ, колье, дубина, рычагъ, рогатина (1773: $81)$.

Bd. 2:

150. БАРАНъ: Овенъ // ОВЕНЪ, баранъ старой (1773: 210).

159. ПЂТЕЛЬ: Куръ // КУРЪ, кочетъ, пЪтель, пътухъ (1773: 147).

161. КУРИЦА: Кокошъ // КОКОШЬ, курица, особенно насђтка и съ цыплятами (1773: 138).

187. ББДА: Горе // ГОРЂ [darunter:] горе (бъда) 1773: 68).

! 191. ЛЂНЬ: ЛЪность // ЛЂНОСТЬ, (поелико есть видъ боязни) медленіе, нерадъніе, косньніе [...] (1779: 131).

204. ВЫСОКО: Горђ // ГОРЂ, наръч. значитъ вверьху, или вверьхъ, высоко, а когда стоит го'ре, тогда разумъть надо зло, бъду, печаль (1773: 68).

222. ХУДО: Зль // ЗЛЂ, наръч. т. е. худо (1773: 104)

258. ДА: Ей // ЕЙ, ЕЙ, нарђч. для подтвержденія истинны, вмъсто божбы употреблять дозволенное (1773: 87).

26o. ГДЂ: Идъже // ИДЂЖЕ, нарьч. гдњ (1773: 105).

261. ЗДЂСЬ: Здђ // ЗДЂ, нарђч. здЂсь, на съмъ мЂсть (1773: 102).

Besondere Beachtung verdient die Parallele bei Nr. 8, denn unter CECTPA ist in den Vocabularia nicht etwa ksl. cecmpa genannt worden (das zweifellos oben eine plausiblere Einordnung des Wortartikels unter 3.1. ermöglicht hätte), sondern сестреница angeführt, obwohl dieses eher "Tochter der Schwester" als "Schwester" bedeutet. ${ }^{41}$ Ist es ein Zufall, daß auch Alekseev gerade diese seltenere Bedeutung registriert hat, oder gibt es hier einen begründbaren Zusammenhang, etwa insofern, als das Vocabularia-Äquivalent von Alekseev abhängt oder beide unabhängig voneinander auf eine dritte Quelle zurückgehen?

4.2. Im Gegensatz dazu war das anonyme, unvollendet gebliebene und erst 1964 gedruckte Wörterbuchmanuskript aus der ersten Hälfte des 18. Jh., das heute

\footnotetext{
${ }^{41}$ Oleg Nikolaevič Trubačev, Istorija slavjanskich terminov rodstva i nekotorych drevnejšich terminov obščestvennogo stroja (Moskva: Izdatel'stvo Akademii nauk, 1959), 67.
} 
gewöhnlich als Werk von Vasilij Nikitič Tatiščev (1686-175o) angesehen wird, ${ }^{42}$ für die Bearbeiter des Pallas-Wörterbuchs möglicherweise nicht erreichbar, auch wenn sie Zugang zum Archiv Tatiščevs hatten. ${ }^{43}$ Unabhängig von der Klärung der Urheberschaft und Erreichbarkeit ist dieses Lexikon aber sehr aufschlußreich, weil es veranschaulicht, wieviele kirchenslavisch-russische Oppositionen überhaupt in dieser meist noch nicht mit Bedeutungsangaben versehenen alphabetischen Wortliste bereits festgehalten worden sind. Unter seinen mehr als 16000 Lemmata ${ }^{44}$ sind zahlreiche Eintragungen, die russisch-kirchenslavische Oppositionsbildungen betreffen, und nicht selten werden diese auch in kirchenlavisch-russischer Anordnung ausgewiesen. $\mathrm{Zu}$ den 273 Wortpaaren der Vocabularia lassen sich über hundert Paarungen ermitteln, wenn man die am Ende stehenden Grundzahlen und die Formvarianten des Infinitivs mitzählt, doch sind keineswegs alle Paare ausdrücklich mit den Buchstaben $p$. und сл. als Gegensatz von russischem und kirchenslavischem Wort ausgewiesen, und man muß auch berücksichtigen, daß die herausgeberin, Aleksandra Petrovna Aver'janova, zwischen zwei Wörtern selbst dann или (!) gedruckt hat, wenn wie in der Mehrzahl der Fälle in der Handschrift nur $u$ (!) steht. ${ }^{45}$ Eindeutig zu lesende Gegensätze, die wie zu Nr. 31 борода - сл. брада und брада - p. борода in beiden Richtungen zum Ausdruck gebracht werden, sind relativ selten, und manchmal handelt es sich wie zu Nr. 9 bei муж eher um Bedeutungsunterschiede als um die Zugehörigkeit zu verschiedenen Sprachen (wie sie im parallelen Fall zu Nr. 1о bеі жена direkt angezeigt wird). In der folgenden Liste werden zur Nummer der Vocabularia die Eintragungen gestellt, die wenigstens ein Wort von deren kirchenslavisch-russischer Paarbildung enthalten; Wörter, die dort nicht genannt sind, werden unterstrichen:

3. папа - отец, р. поп 264

4. мать - матерь 173

6. дочь - сл. дщерь 94; дщерь - дщи 97

9. муж - супруг, сожитель 185; муж - муский [sic!] пол 185

10. жена - р. женщина; жена - сл. супруга 105; женщина - сл. жена 104

12. отрок - отроча, юноша, раб, р. малой, служитель 258

13. дитя - младенец,89; дитя - чадо 89; младенец - дитя 178; отроча - дитя, младенец 258

15. люди - человеки 171

16. глава - р. голова 72; голова или глава 76

17. лице - р. лицо 166

20. глазъ - сл. око 73; око - р. глаз 239

24. лоб или чело 166

25. влас или волос 58; волос - сл. влас 62

26. ланита - р. щека 161

27. рот - сл. уста, устне 362

28. горло 77; гортань или горло 78

31. борода - сл. брада 46; брада - р. борода 47

\footnotetext{
${ }^{42}$ Rukopisnyj leksikon pervoj poloviny XVIII veka. Podgotovka k pečati A. P. Aver'janovoj (Leningrad: Izdatel'stvo Leningradskogo universiteta, 1964).

${ }^{43}$ Comtet, "Le dictionnaire plurilingue de Pallas," 12.

${ }^{44}$ Rukopisnyj leksikon pervoj poloviny XVIII veka, 3.

${ }^{45}$ Ibid., 63 Anm. 4.
} 
32. выя - р. шея 71

33. плече - плечо 274; рамо - плече 355

36. палец - сл. перст 263

37. ноготь - сл. ногть 214; пазнокть - ноготь 263; пазнокть 263

38. брюхо 49; ивот - утроба 105

47. млеко - р. молоко 179; молоко - сл. млеко 182

53. глас или голос 73; голос - сл. гласъ 76

55. кличь - $\underline{\text { 3ов } 141}$

57. вой - плач, вопль; воп - крик, сл. вопль 63; вопль - р. крик 63; крик - сл. вопль 154

58. глагол - речение 73; речь - сл. глагол 359

6о. любы - р. любовь 170

61. резь - боль 357; недуг - нега, болезнь, скорбь 205

63. работа - труд 401

65. мочь - можность, сл. мощь 184

67. брак или свадба 47; венчание - супружества, брак 54; сопряжение - брак 386

68. живот - жизнь 105

69. раст - р. рост 356; рост - возрост 362; рост - дихва 362

71. кончина - смерть, преставление 147; кончина - света преставление, конец мира 147

74. пуля - пулка, шар 331

76. уна или месяц 169; месяц или луна 176; месяц - р. месец 176

88. ночь - сл. нощь 215; нощь - р. ночь 215

93. есень - р. осень102; осень - сл. есень 246

95. лето - год 164

96. пора - время, час 295

104. персть - прах 269; прах - порох, пыль зо3; пыль - прах 332

107. брег - берег реки 48

112. огнь - р. огонь 232; огонь - сл. огнь 233

113. зной - жар 123

117. длина - сл. долгота 89

118. дыра - дира

119. нора - яма 215; ров - яма, дол 361

120. рвина - ров 356; ров - яма, дол 361

121. камык - р. камень 136

122. злато - золото 121; золото - сл. злато 124

123. серебро - сл. сребро 377

126. бор - лес 46; дубрава - дуброва 97; лес - сл. дебрь, бор 164

128. дерево или древо 87; древо - дерево 95

130. зелень - злак 119; злак - р. зелень 121

132. пень - корень дерева 265

134. овощь -

138. весь - село 55; село - сл. весь 376

145. глиста - р. червь 73

148. вол - бык 61 
149. корова - сл. крава 149; крава - р. корова 151

150. овень - агнец, боран 231

152. конь - лошедь верховая 146; лошадь - конь 168

154. пес - р. сабака 269

159. кур - петух 159; петел - р. петух 270

161. кокошь - курица, наседка 144

165. орало - соха, плух, косуля, прямуха 245; рало - соха, плуг, осуля, орало

355; соха - чем пашут 386

171. город - град живущий 77 ; град - р. город 78

172. очаг - огнище 261

174. кадь - кадка 134

182. крадца - р. вор 152

184. караул - татарск. стража 137; сторож - сл. страж 391; стражь - р. сторож 391

185. котора - p. распря 151

186. бой или битва 45; драка - сл. битва 95

187. горе - горесть, беда 77; напасти - беды 196

189. брань или война 47; рать - война 356; ратоборство - битва, война, брань 356

190. ратник - воин 356

191. лень или леность 164; леность - р. лень 164

192. лад - согласие 160

193. родины - сл. рождение 361; рождество - р. родины 362

210. красно - сл. червлено 152

212. остро - р. востро 250

218. красно - сл. лепо 152; лепотне - лепо, изрядне 164

222. [злее - хуже, злобнее] 122

227.есть - сл. ясти 102; кушати - ести, вкусити 160

231. почивати - спати 302

233. емлю или. беру 102; имати - брати, ловити 132

239. орати - р. пахати 245

258. ей или воистинно 101

259. несть - р. нет 211; нету или нет 212; ни - ниже, р. нет 212

261. зде - р. здеся 119

266. еда - когда 99; коли - сл. когда, аще 144

267. ныне - сл. днесь 216 теперь - сл. ныне 396

268. первее - прежде, наперед 266

269. после - опосле 297

270. како или как 135

271. кроме - сл. разве; окроме 155; окром - окроме; сл. разве 239; разве кроме, без. 335; разве или кроме 336

272. либо - союз некогда за или 165; дюбо - р. или 170

273. вось, вося, вота - сл. се 64; вотъ, вося, сл. се 65; на - сл. се, сарм. вот 189

един - р. один 99; один - сл. един 235

семь - сл. седмь 376

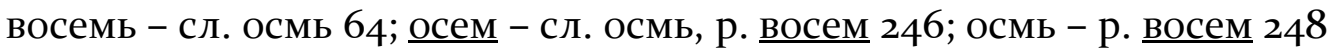


мыти - р. мыть 188; пети - р. петь 270 u. а.

Tatiščevs allzu mechanisches und auch vor künstlichen Bildungen nicht zurückschreckendes Kontrastierungsverfahren ist in neuerer Zeit sehr kritisch beurteilt worden, ${ }^{46}$ aber auch mit seinen Mängeln erweist es sich schon durch die zahlreichen hier unterstrichenen zusätzlich einbezogenen Wörter als ein anderer Zugang zum kirchenslavisch-russischen Wortschatzvergleich, als er bei Alekseev und wiederum anders in den Vocabularia vorliegt.

4.3. Zusammenfassend ist wohl festzustellen, daß trotz mancher Artikelparallelen weder das Wörterbuch Alekseevs noch dasjenige Tatiščevs eine maßgebliche Rolle bei der Besetzung der kirchenslavischen Zeile bei Pallas gespielt haben kann, aber diese Parallelen zeigen auch, daß die Eintragungen in den Vocabularia comparativa nicht ganz untypisch für die noch recht diffusen Vorstellungen sind, die man im Rußland des 18. Jh. von den Unterschieden zwischen kirchenslavischem und russischem Wortschatz gehabt hat. Im Sinne Živovs könnte man wohl sagen, daß auf dieser Zeile ein „hybrides“ Kirchenslavisch zu lesen ist. Vermutlich stammen diese Informationen von einer Person, die einer solchen Aufgabe zwar nicht in jeder Hinsicht gewachsen war, aber doch über eine gewisse Kenntnis des Kirchenslavischen und seiner Besonderheiten im Verhältnis zum Russischen verfügte. Auch wenn es wahrscheinlich nicht mehr gelingen wird, diese Person ohne die Hilfe des Zufalls zu identifizieren, ${ }^{47}$ sollte man wenigstens noch versuchen, einigen der vorläufig noch rätselhaften Entsprechungsvorschläge wie z.B. dem semantisch problematischen сестреница unter Nr. 8. CECTPA auf den Grund zu gehen. Mindestens ebenso seltsam wie diese wahrscheinlich als Fehler zu wertende Angabe und gleichfalls klärungsbedürftig ist das schon erwähnte Auftreten der Infinitive ни'кнути/нидати unter Nr. 69. РОСТЪ, nicht nur wegen des unpassenden 2 anstelle eines $\mathrm{zu}$ erwartenden $\kappa,{ }^{48}$ sondern auch deshalb, weil hier mit diesem im Schrifttum nicht gerade häufigen Verb möglicherweise ein Wort aus der kirchenslavischen Übersetzung des Alten Testaments genutzt worden ist ${ }^{49}$ und mit der Stelle aus 3. Mose 25,5 “Никнущая о себъ нива" /

\footnotetext{
${ }^{46}$ Vgl. Viktor Markovič Živov, Kul'turnye konflikty v istorii russkogo literaturnogo jazyka XVIII - načala XIX veka (Moskva: Institut russkogo jazyka AN SSSR, 1990), 44-47; idem., Jazyk i kul'tura v Rossii XVIII veka (Moskva: Škola “Jazyki russkoj kul'tury,” 1996), 191-194.

47 Selbst der speziell das 18. Jh. betreffende Kirchenslavisch-Artikel im ersten Band der PetersburgEnzyklopädie geht nicht einmal auf die im Umfeld der Akademie in dieser Stadt entstandenen Bibelkonkordanzen ein - geschweige denn auf die hier vorgestellten kirchenslavischen WortschatzExplorationen im allerhöchsten Auftrag der Zarin! Vlg. Dmitrij Grigor'evič Demidov, “Cerkovnoslavjanskij (cerkovno-slavjanskij) jazyk,” in Tri veka Sankt-Peterburga. Enciklopedija v trech tomach. Tom 1. Os'mnadcatoe stoletie. Kniga vtoraja. N-Ja. Otvetstvennyj redaktor Petr Evgen'evič Bucharkin (Sankt-Peterburg: Filologičeskij fakul'tet SPbGU, 2001), 508-511.

${ }^{48}$ Vgl. Étimologičeskij slovar' slavjanskich jazykov. Praslavjanskij leksičeskij fond. Vypusk 25. Pod redakciej O. N. Trubačeva. Moskva: Nauka, 1999), 114-115 zu *nikati/*niknoti.

${ }^{49}$ Izmail Ivanovič Sreznevskij, Materialy dlja slovarja drevne-russkogo jazyka po pis'mennym pamjatnikam. 1-3, Dopolnenija (Sanktpeterburg: Imperatorskaja Akademija nauk, 1893-1912), 2 (1895), 450.
} 
"Ager, tellus, humus, qui sponte gignitur" 50 auch Eingang in die lexikographische Tradition schon des 17. Jh. gefunden hat. Unabhängig von den Problemen, die die kirchenslavische Zeile aufwirft, bedürfen gewiß weiterer Nachforschungen zudem die hier zutagegetretenen französischen Interferenzen bei der Festlegung der russischen Lemmata des Pallas-Wörterbuchs und die jetzt nicht mehr ganz auszuschließenden nachteiligen Folgen, die das Nebeneinander der vier Sprachen Russisch, Latein, Deutsch und Französisch im Modèle du vocabulaire von 1786 bei der Ermittlung der Äquivalente in den einzelnen Sprachen möglicherweise gehabt hat. Und daß die Vocabularia comparativa in der Slavistik mehr Aufmerksamkeit verdienen, als ihnen bisher gewidmet worden ist, sollte auch in diesem Aufsatz deutlich geworden sein.

$5^{\circ}$ Johan Gabriel Sparwenfeld, Lexicon Slavonicum. Edited and commented by Ulla Birgegård. Vol. I-IV, Index. (Acta Bibliothecae R. Universitatis Upsaliensis, Vol. XXIV, 1-5) (Uppsala, 1987-1992), 2 (1988), 263 (Nr. 5042); vgl. Leksykon slovenoros'kyj Pamvy Beryndy, 77 und Leksykon latyns'kyj Je. Slavynec'koho, 477. 